\title{
Effect of Thermocycling on the Compressive Strength of Selected Luting Cements
}

\author{
Al-Khadim Aws H. ${ }^{\mathrm{a}}$, Abdullah H. ${ }^{\mathrm{b}}$, Al-Ani Sarah T. ${ }^{\mathrm{c}}$ \\ ${ }^{\mathrm{a}}$ Faculty of Dentistry, Islamic Science University of Malaysia \\ ${ }^{\mathrm{b}}$ Faculty of Dentistry, University of Malaya. \\ ${ }^{\mathrm{c}}$ Faculty of Medicine, MAHSA University.
}

\section{ABSTRACT}

Introduction: The purpose of this in vitro study was to evaluate the effect of thermocycling on the compressive strength of selected luting cements. Material and methods: 5 types of luting cements were tested. A total of thirty cylindrical specimens measuring $6 \mathrm{~mm}$ in height and $4 \mathrm{~mm}$ in diameter were prepared for each type of cement which were then divided into two groups ie Group 1: Exposure, and Group 2: Control. Both groups were stored in distilled water at $37^{\circ} \mathrm{C}$ for 24 hours. Group 1 was subjected to 500 cycles in a thermocycling baths of $5^{\circ} \mathrm{C}$ and $55^{\circ} \mathrm{C}$ with 20 seconds in each bath. Group 2 was not exposed to thermocycling procedure. The compressive strength for each cement type was determined by using a universal testing machine. Results: Resin adhesive cement had the highest compressive strength; followed by conventional glass ionomer cement (GIC) whilst resin modified GIC was the least. Thermocycling had no significant effect on the compressive strength of RelyX ${ }^{T M}$ ARC and Fuji I ( $\left.p>0.05\right)$, but a significant effect on Fuji I CAPSULE, Fuji CEM, Fuji Plus CAPSLUE $(p<0.05)$ was observed. Conclusion: The effect of thermocycling on the compressive strength of luting cements differed considerably with respect to their chemical compositions.

KEYWORDS: thermocycling, compressive strength, luting materials.

\section{INTRODUCTION}

A variety of materials are commercially available as luting agents, which are used in fixed dental prosthesis. These materials are usually subjected to mechanical and thermal stresses, and are exposed to challenging oral environmental conditions. Their main function is to provide retention by interlocking minor irregularities on the prepared tooth surface of the restoration. ${ }^{1}$ In order to function well, cements must set reasonably fast after mixing and must also show good resistance to erosion in the oral environment ${ }^{2}$ otherwise the materials may fail to maintain their integrity and function either in the short or long term. Failure may happen because of

Corresponding Author:

Dr. Aws H. Ali Al-Kadhim

Faculty of Dentistry USIM,

Level 15, Menara B, Persiaran MPAJ

Jalan Pandan Utama, Pandan Indah,

55100 Kuala Lumpur.

Phone: 603-42892430 /0163191490

Fax: 603-42892522

Email:awsimail@yahoo.com mechanical, chemical, electrochemical, physical deficiencies or degradation. Mechanical and thermal causes may lead to failure of cohesion (attractive forces within the same material) or adhesion (attractive forces binding two different materials across their interface). These failures may result from the inability of the material to withstand the imposed stresses or environment, or from the cumulative effects of both. Comprehensive evaluation and understanding of different properties of luting cements are critically important before using them in clinical application. ${ }^{3}$

A perfect luting cement should have physicomechanical properties, which look like those of the dentine. The cement properties usually tested are the compressive and diametral tensile strength, modulus of elasticity and fracture toughness. High compressive strength along with high rigidity are mandatory to resist the forces of mastication. ${ }^{1,3}$ Caries and crown dislodgments are the most common causes for failure of crowns and bridges. Caries may 
also lead to cement microfracture and consequently microleakage. The dislodgment may be related directly to gross mechanical failure of luting cements. $^{4}$

Resin bonded luting agents have been available for some time. The early materials developed in the 1950s were primarily based on acrylic resin chemistry. More recently, resin cement development has been based on the adoption of the chemistry of resin composites and adhesives. ${ }^{3}$ They are available in various shades and opacities and their chemical compositions allow them to adhere to many dental substrates. ${ }^{5}$

Glass ionomer cement has been introduced since 1970s, and it is a favourite choice of luting cement due to several advantages like its ionic exchange bonding to the tooth structure, and fluoride release. Many techniques have been carried out to explain the complicated microstructure of glass ionomer cement including chemical analysis, optical microscopy, infrared spectroscopy, electron microscopy (both transmission and scanning), and $\mathrm{x}$ ray microanalysis. Each of these techniques has contributed to the understanding of the setting reaction, composition and microstructure of glass ionomer cements. ${ }^{6}$

In order to overcome the foregoing limitations of conventional glass ionomer cements, but yet preserve the benefits, the concept of resin modified glass ionomer was formulated. ${ }^{7}$ This has almost the same chemical composition of conventional glass ionomer cement with the addition of polycarboxylic acid polymer and modified with pendent methacrylate groups, water and hydrophilic methacrylate monomer.

Compressive strength is the maximum compressive stress to which a material can be subjected before it fails. The test is done with cylindrical specimens. ${ }^{3}$ Compressive strength is considered a critical indicator for the success of luting cements because a high compressive strength is necessary to tolerate masticatory forces. ${ }^{8,10}$ The most widely recognized mechanical properties for characterizing luting cements are compressive strength and flexural. ${ }^{9}$

Thermocycling is the in-vitro process of subjecting a restoration and a tooth to temperature changes like those found in the oral cavity. Mechanical stresses induced by temperature changes can directly induce crack propagation of the bonded surfaces, according to a study done by Gale and Darvell (1999) and Chadwick (1994) who measured the effect of thermocycling on the compressive strength of three commercial composites. Both studies concluded that there were significant differences in the mean compressive strength for all materials. ${ }^{11,12}$ Many thermal aging regimes have been cited in the literature with $37^{\circ} \mathrm{C}$ often being chosen as an appropriate temperature for constant temperature aging, ${ }^{13}$ although some thermal cycling with extremes of temperature based on in-vivo thermocouple studies had used temperatures ranging between $0-67^{\circ} \mathrm{C} .{ }^{14}$ No evaluations have been reported for the compressive strength of new adhesive luting cements. The strengths of these materials vary considerably because of their various components and setting mechanisms. ${ }^{8}$

It was concluded that some of the observed behaviour might have potential detrimental consequences on the long-term clinical durability of the materials tested. The aims of this study were i) to measure the effect of thermocycling on the compressive strength of each type of luting cement, and ii) to compare the effect of thermocycling on compressive strength between all the types of luting cement.

\section{MATERIALS AND METHODS}

Five types of luting cements were used in this study as shown in Table 1.

Table 1: Luting cements used in this study

\begin{tabular}{|c|c|c|c|}
\hline $\begin{array}{l}\text { Luting } \\
\text { agent }\end{array}$ & $\begin{array}{l}\text { Product } \\
\text { Name }\end{array}$ & Manufacturer & $\begin{array}{l}\text { Batch } \\
\text { number }\end{array}$ \\
\hline $\begin{array}{l}\text { Resin } \\
\text { adhesive } \\
\text { cement }\end{array}$ & $\begin{array}{l}\text { RelyX }^{T M} \\
\text { ARC }\end{array}$ & $\begin{array}{l}3 M \text { ESPE, } \\
\text { USA }\end{array}$ & $\begin{array}{l}\text { LOT } \\
20080619\end{array}$ \\
\hline $\begin{array}{l}\text { Glass } \\
\text { ionomer } \\
\text { cement } \\
\text { hand-mixed }\end{array}$ & Fuji I & $\begin{array}{l}\text { GC } \\
\text { Corporation, } \\
\text { Tokyo, Japan }\end{array}$ & $\begin{array}{l}\text { LOT } \\
0707231\end{array}$ \\
\hline $\begin{array}{l}\text { Glass } \\
\text { ionomer } \\
\text { cement } \\
\text { capsulated }\end{array}$ & $\begin{array}{c}\text { Fuji I } \\
\text { CAPSULE }\end{array}$ & $\begin{array}{l}\text { GC } \\
\text { Corporation, } \\
\text { Tokyo, Japan }\end{array}$ & $\begin{array}{l}\text { LOT } \\
0712181\end{array}$ \\
\hline $\begin{array}{l}\text { Resin } \\
\text { modified } \\
\text { glass } \\
\text { ionomer } \\
\text { cement } \\
\text { hand-mixed }\end{array}$ & Fuji CEM & $\begin{array}{l}\text { GC } \\
\text { Corporation, } \\
\text { Tokyo, Japan }\end{array}$ & $\begin{array}{l}\text { LOT } \\
0710241\end{array}$ \\
\hline $\begin{array}{l}\text { Resin } \\
\text { modified } \\
\text { glass } \\
\text { ionomer } \\
\text { cement } \\
\text { capsulated }\end{array}$ & $\begin{array}{l}\text { Fuji Plus } \\
\text { CAPSULE }\end{array}$ & $\begin{array}{l}\text { GC } \\
\text { Corporation, } \\
\text { Tokyo, Japan }\end{array}$ & $\begin{array}{l}\text { LOT } \\
0801245\end{array}$ \\
\hline
\end{tabular}


Each type of luting cement consisted of thirty specimens $(n=30)$ and was divided into two groups; Exposure Group: consisted of fifteen specimens $(n=15)$ stored in distilled water for 24 hours at $37^{\circ} \mathrm{C}$ with at least $90 \%$ relative humidity and exposed to 500 cycles of thermocycling temperatures of $5^{\circ} \mathrm{C}$ and $55^{\circ} \mathrm{C}$; and Control Group: consisted of fifteen specimens $(\mathrm{n}=15)$ stored in distilled water for 24 hours at $37^{\circ} \mathrm{C}$ with at least $90 \%$ relative humidity.

All the materials were mixed according to the manufacturers' instructions. For Fuji I, the handmixed conventional glass ionomer cement (one scoop of powder and two drops of liquid); was mixed with a plastic spatula and a paper pad for 20 seconds. For Fuji I CAPSULE and Fuji Plus CAPSULE which were the encapsulated cements; were mixed by rotation using RotoMix, (3M, EPSE, Seefeld, Germany) for 10 seconds without centrifuge as recommended, the nozzle was inserted into the cavity of the mould whilst touching the wall of the mould. The nozzle was raised slowly as the mould was filled as shown in Figure 1. For paste cements ie Fuji CEM and RelyX ${ }^{\mathrm{TM}} \mathrm{ARC}$, an equal amount of paste was extruded from the paste-pack cartridge loaded onto a dispenser provided by the manufacturer and dispensed on a paper pad and mixed by a plastic spatula for 10 seconds as recommended.

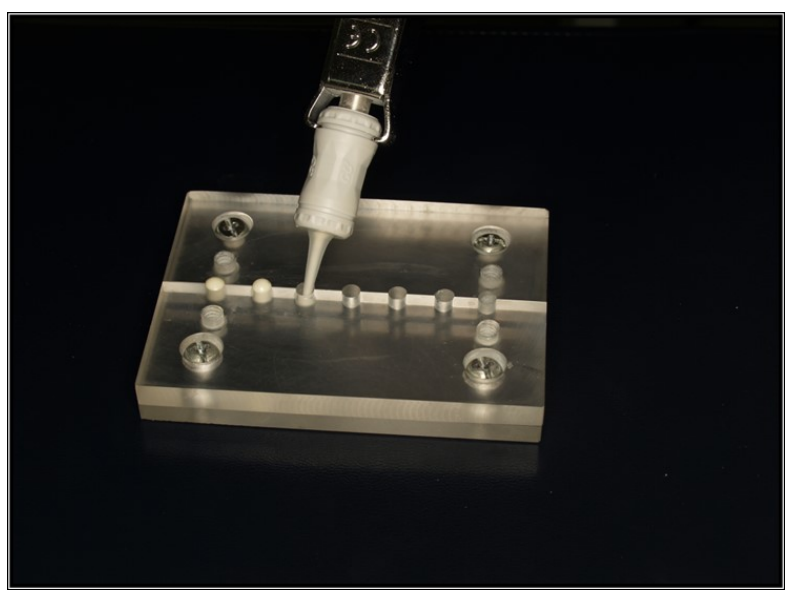

Figure 1: The procedure to make encapsulated cements for Fuji I CAPSULE and Fuji Plus CAPSULE. The nozzle was inserted into the cavity of the mould whilst touching to the wall of the mould. The nozzle was raised slowly as the mould was filled.

The procedure was performed in a room at $23^{\circ} \mathrm{C}$. The humidity was not controlled but was around $50 \%$ relative humidity. All specimens were prepared in a similar manner by one person to minimize error and bias. Thirty test specimens $(n=30)$ were prepared in a cylindrical polytetrafluroethylene split moulds, with internal dimensions of $6 \mathrm{~mm}$ high and 4 $\mathrm{mm}$ in diameter. The dimensions of the specimens were measured with a micrometer screw gauge (Kawasaki, Japan) accurate to 10 $\mu \mathrm{m}$ (Figure 2). Within 60 seconds after mixing, a slight excess of the mixed luting cement was placed into the mould, which was resting on a polyester strip in order to prevent the adhesion of polyacrylic acid-based cements.

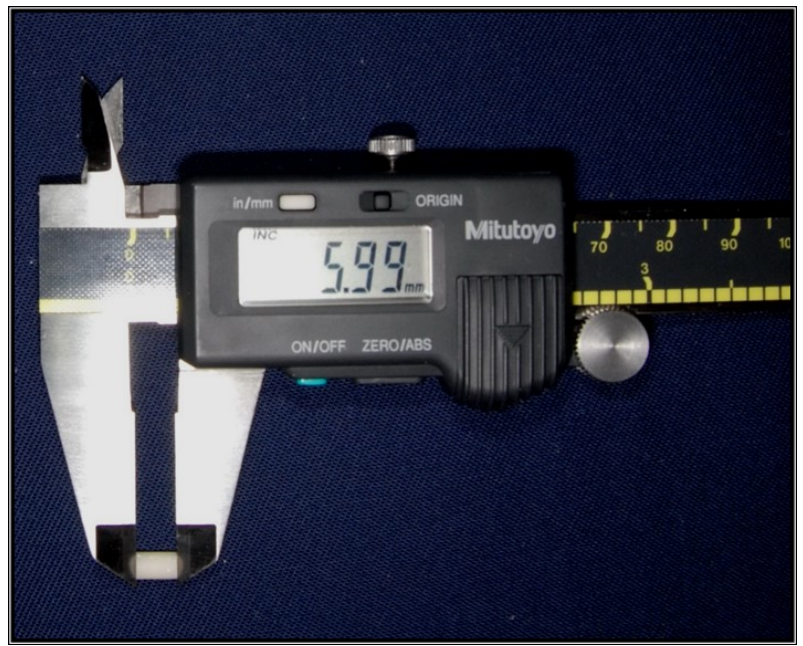

Figure 2: Micrometer screw gauge (Kawasaki, Japan) was used to measure the dimensions of the specimens accurate to $10 \mu \mathrm{m}$.

One hundred and eighty seconds after mixing, the whole assembly of the specimens and mould were placed in an environmental chamber (incubator) at $37^{\circ} \mathrm{C}$ and a relative humidity of at least $90 \%$ for one hour. Exactly one hour after placing in the incubator, the plates were removed and the end of the specimens were grounded flat at right angle to its long axis by using a 800 -grit silicon carbide paper under continuous water irrigation using a Twin Wheel Grinder/Polisher machine (Buehler UK, Conventry, England). In order to facilitate the removal of the hardened cement specimens, the internal surfaces of the mould were evenly coated with paraffin wax. The luting cements specimens were carefully removed from the moulds and then stored in distilled water in the environmental chamber at $37^{\circ} \mathrm{C}$ for 23 hours. Specimens with defects were not used for the study.

\section{Evaluation of Compressive Strength}

The universal testing machine used in this study was SHIMADZU (SHIMADZU Corporation, Kyoto, Japan). The flat end of the specimens were attached with a wet piece of filter paper to make sure the specimens were tested "wet" and a compressive load applied, with a cross head speed of $0.5 \mathrm{~mm} / \mathrm{min}$ to the long axis of the specimen. The maximum load to failure was recorded and the procedure repeated so that the 
minimum of 30 nominally identical standard cylindrical specimens had been fractured for each type of luting cement (Control Group: $n=15$, Exposure Group: $n=15$ ).

\section{Thermocycling Procedure}

Fifteen specimens for each type of luting cement were stored in distilled water at $37^{\circ} \mathrm{C}$ in at least $90 \%$ relative humidity in an incubator for 24 hours prior to the thermocycling procedure. The thermocycling machine used in this study was Neslab Thermocycler (Neslab Instruments Inc., USA). The two baths were filled with distilled water and the temperature was controlled at $55^{\circ} \mathrm{C}$ for the hot bath and $5^{\circ} \mathrm{C}$ for the cold bath using a thermostat. The specimens underwent 500 cycles of thermocycling. Each specimen was in the respective baths for 20 seconds and transfer time between baths was 3 seconds.

The temperatures of both baths were checked regularly using two separate thermometers. The temperatures were maintained at all times at $\pm 1^{\circ} \mathrm{C}$. The specimens were placed in a soft wire mesh that was secured tightly to the specimen holder with the help of threads. Once the thermocycling period has ended, the specimens were removed from the specimen holder and wire mesh, and then placed between the two plates of the universal testing machine to measure the compressive strength.

\section{Statistical Analysis}

The data was analysed using SPSS version 21 . Nonparametric Mann-Whitney $U$ test was used to determine the effect of thermocycling on the compressive strength between exposure group and control group for each type of luting cement at $p<$ 0.05 level of significance.

\section{RESULTS}

The effect of thermocycling on the compressive strength for each types of luting cements used in this study is shown in Table 2. There were no effect of thermocycling on the compressive strength of RelyX ${ }^{T M}$ ARC $(p=0.983)$ and Fuji I $(p=0.756)$. However, for encapsulated glass ionomer cement ie Fuji I CAPSULE, Fuji CEM and Fuji Plus CAPSULE; thermocycling effected the compressive strength, $p=0.033, p=0.003$ and $p=0.036$ respectively.
Table 3: The effect of thermocycling on the compressive strength for each types of luting cements used in this study.

\begin{tabular}{|c|c|c|c|c|}
\hline \multirow[b]{2}{*}{$\begin{array}{l}\text { Luting } \\
\text { cement }\end{array}$} & \multicolumn{2}{|c|}{$\begin{array}{c}\text { Compressive Strength* } \\
(\mathrm{MPa})\end{array}$} & \multirow[b]{2}{*}{$\begin{array}{l}\text { Z } \\
\text { statistic }\end{array}$} & \multirow[b]{2}{*}{$\mathrm{value}^{\mathrm{a}}$} \\
\hline & $\begin{array}{l}\text { No } \\
\text { thermo- } \\
\text { cycling } \\
\text { (Control } \\
\text { group) } \\
(\mathrm{n}=15)\end{array}$ & $\begin{array}{l}\text { With } \\
\text { thermocycling } \\
\text { (Exposure } \\
\text { group) } \\
(n=15)\end{array}$ & & \\
\hline $\begin{array}{l}\text { RelyX } \\
\text { ARC }\end{array}$ & $\begin{array}{l}249.160 \\
(45.28)\end{array}$ & $\begin{array}{l}245.631 \\
(37.926)\end{array}$ & -0.21 & 0.983 \\
\hline Fuji I & $\begin{array}{l}154.587 \\
(58.16)\end{array}$ & $\begin{array}{l}142.671 \\
(69.082)\end{array}$ & -0.311 & 0.756 \\
\hline $\begin{array}{l}\text { Fuji I } \\
\text { CAPSULE }\end{array}$ & $\begin{array}{l}162.975 \\
(78.04)\end{array}$ & $\begin{array}{l}112.788 \\
(92.233)\end{array}$ & -2.136 & $0.033^{a}$ \\
\hline Fuji CEM & $\begin{array}{l}101.777 \\
(15.11)\end{array}$ & $\begin{array}{l}91.086 \\
(21.376)\end{array}$ & -3.007 & $0.003^{a}$ \\
\hline $\begin{array}{l}\text { Fuji Plus } \\
\text { CAPSULE }\end{array}$ & $\begin{array}{l}96.033 \\
(27.508)\end{array}$ & $\begin{array}{l}86.975 \\
(26.343)\end{array}$ & -2.095 & $0.036^{a}$ \\
\hline
\end{tabular}

*Median (IQR), ${ }^{a}$ Mann-Whitney $U$ test, significance level was $p<0.05$.

\section{DISCUSSION}

The most widely recognized mechanical properties for characterizing luting cements are compressive strength and flexural strength. ${ }^{9}$ Compressive strength has been considered as a critical indicator for the success of the luting cements because high compressive strength is necessary to tolerate the masticatory forces. ${ }^{8,10}$

In this study, the compressive strength was defined as the stress at which a material fractured..$^{11,12}$ Although luting cements are partly exposed to the saliva in-vivo, however there is a possibility of in-vivo aqueous contamination, perhaps via the dentinal tubules or from the marginal microleakage. ${ }^{13,14}$ Water and not saliva was used in this study. The primary effect of saliva may be due to its water content, but its $\mathrm{pH}$ and buffering capacity may also influence the setting and maturation of dental cements. ${ }^{15-17}$

Comparison of the results from different studies is critical, since there is no generally accepted standard for some experimental parameters, such as type and duration of thermocycling. This current study showed that considerable differences in the compressive strengths were recorded between the tested luting cements. According to this study, compressive strength of luting cements ranged from the highest to the lowest are in the following order: i) resin adhesive cement, ii) conventional glass ionomer cement, and iii) resin modified glass ionomer cements. This ranking of materials according to compressive strength is in accordance with other reports. ${ }^{18-20}$ In this current study, 
thermocycling had no significant effect on the compressive strength of resin adhesive cement (RelyX ${ }^{\mathrm{TM}}$ ARC), while thermocycling had a significant effect on the compressive strength of both types of resin modified glass ionomer cements (Fuji CEM, Fuji Plus CAPSULE). This could be related to the differences in their chemical compositions; for conventional glass ionomer cement, the powder in these materials were finely ground calcium aluminium fluorosilicate glass with particle size around $25 \mu \mathrm{m}$ for luting materials, and the liquid was $50 \%$ aqueous solution of polycyclic acid or other polycarboxylic acid copolymer that contained about $5 \%$ tartaric acid. In some materials, the copolymer is added to the powder while the liquid will contain the tartaric acid; in others all the ingredients are in the powder and the liquid is water. For resin modified glass ionomer cement, it has the same basic ingredients of conventional glass ionomer cements with incorporation of resin mainly polyHEMA (Poly-hydoxy-ethyl-methacrylate) in its matrix, due to the fact that resin modified glass ionomer has been shown to exhibit high water absorption, which has been related to the presence of polyHEMA (Poly-hydoxy-ethyl-methacrylate) and unconverted monomer in the set cement. ${ }^{21-23}$ This water uptake could lead to the reduction of compressive strength due to hydrolysis of some cement components. ${ }^{24}$ Furthermore, stronger cements seemed to provide more even stress distribution, less probability to failure hence greater probability for clinical success. ${ }^{10}$

The present result is in agreement with previous studies done by Nicholson et al (1992) where they found that due to the presence of hydrophilic species, the resin modified glass ionomer cement were expected to absorb water easily, and this water uptake would reduce the compressive strength. ${ }^{21}$ This study showed that thermocycling had no effect on the compressive strength of handmixed glass ionomer cement (Fuji I), while thermocycling decreases the values of the compressive strength of encapsulated glass ionomer cement (Fuji I CAPSULE). This could be related to the fact that the percentage of porosity in Fuji I CAPSULE cements is significantly higher than that of Fuji I, and according to previous study done by McCabe, ${ }^{23}$ porosity will act as a reservoir for water within the structure of material in which water can be retained and transported through the cement structure. They also found that increasing the percentage of porosity would lead to an increase in the amount of water absorption, which would lead to decrease amount of compressive strength due to hydrolysis of some cement components. ${ }^{24}$

From this study, luting cements with the highest compressive strength was resin adhesive cement (RelyX ${ }^{T M}$ ARC), followed by conventional glass ionomer cement (Fuji I, Fuji I CAPSULE) and resin modified glass ionomer cement (Fuji CEM, Fuji Plus CAPSULE). The effect of thermocycling on the compressive strength of luting cements differed considerably with respect to the chemical composition of the luting cements. In using resin modified glass ionomer cement for fitting/luting laminated porcelain veneers should not be compensated by thickness of luting agent as this may cause crack propagation in the veneers.

\section{Conflict of interest:}

The authors certify that they have no affiliations with or involvement in any organization or entity with any financial interest (such as honoraria; educational grants; participation in speakers' bureaus; membership, employment, consultancies, stock ownership, or other equity interest; and expert testimony or patent-licensing arrangements), or nonfinancial interest (such as personal or professional relationships, affiliations, knowledge or beliefs) in the subject matter or materials discussed in this manuscript.

\section{REFERENCES}

1. Smith, B. G., Wright, P. S., and Brown, D. The critical handling of dental materials, $2^{\text {nd }} \mathrm{ed}$. Butterworth-Hienemann: Oxford 1995: 83-86.

2. Nicholson, J. W., and McKenzie, M. A. The properties of polymerizable luting cements. $J$ Oral Rehabil 1999; 26(10): 767-774.

3. Dhuru, V. B. Contemporary Dental Material. Manzar Khan, Oxford university press. 2004: 2543.

4. Tuna, S. H., Keyf. Water Sorption and Solubility of Provisional and Permanent Luting Cements. Tur Dent J2006; 30(3): 19-24

5. Diaz-Arnold, A. M., Vargas, M. A. and Haselton, D. R. Current status of luting agents for fixed prosthodontics. J Prosthet Dent 1999; 81(2): 135141.

6. Swift, E. J., and Dogan, A. U. Analysis of glass 
ionomer cement with use of scanning electron microscopy. J prosthet Dent 1990; 64 (2): 167174.

7. McComb D., and Nathanson D. Glass -ionomer luting cements. In: Davidson, C. L., and Mjör, I. A. Advanced in Glass ionomer cement. Quintessence Publishing Co. 2001:149-170.

8. White, S. N., and Yu, Z. Compression and diametral tensile strengths of current adhesive luting agents. J Prosthet Dent 1993; 69 (4): 568572.

9. Xie, D., Brantley, W. A., Cullbertson, B. M., and Wang, G. Mechanical properties and microstructure of glass ionomer cements. Dent mater 2000; 16(2): 129-138.

10. Piwowarczyk, A., and Lauer, H. Mechanical properties of luting cements after water storage. Oper. Dent 2003; 28 (5): 535-542.

11. Chadwick, R. G. Thermocycling - the effects upon the compressive strength and abrasion resistance of three composite resins. J Oral Rehab 1994; 21(5): 533-543.

12. Gale, M. S., and Darvell, A. W. Thermal cycling procedures for laboratory testing of dental restoration. J Dent 1999; 27, 89-99.

13. Smith, R. M., Barrett, M. G., Gardener, W. A., Marshal, T., Mclean, M. J., McMicheal, D. W., Yerbury, P. J. abd Rawls H. R. Effect of environmental stress on resin to metal bond. AM J of Dent 1993; 6: 111.

14. Ozden, A. N., Akaltan, F., and Can, G. Effect of surface treatments of porcelain on the shear bond strength of applied dual-cured cement. $J$ prosthet Dent 1994; 72(1): 85-88

15. Fleming, G. J., Farooq, A. A., and Barralet, J. $E$. Influence of powder/liquid ratio on performance of restorative glass-ionomer cement. Biomaterials 2003; 24(23): 4173-4179.

16. Nomoto, R., and McCabe, J. F. Effect of mixing methods on the compressive strength of glass ionomer cement. J Dent 2001; 29:205-210.

17. Cattani-Lorente, M. A., Dupuis, V., Moya, F., Payan, J., and Meyer, M. Comparative study of the physical properties of a polyacid-modified composite resin and a resin-modified glass ionomer cement. Dent Mater 1998; 15(1), 21 32.

18. Kwon, Y. H., Kwon T. Y., Ong J. L., and Kim K. $H$. Light polymerized compomers: coefficient of thermal expansion and microhardness. $J$ Prosthet Dent 2002; 88(4): 396-401

19. Nomoto, R., Komoriyama, M., McCabe, J. F., and Susumu Hirano. Effect of mixing method on the porosity of encapsulated glass ionomer cement. J Dent 2004; 20: 972-978.

20. Li, Z. C., and White, S. N. Mechanical properties of dental luting cements. J Prosthet Dent 1999; 81(5): 597-609.

21. Nicholson, J. W., Anstice, H. M., and McLean, J. W. A preliminary report on the effect of storage in water on the properties of commercial lightcured glass ionomer cements. Br Dent J 1992; 173(3): 98-101

22. Milutinović-Nikolić A. D., Medić V., B., and Vuković Z. M. Porosity of different dental luting cements. Dent Mater 2006; 23 (6): 674-678

23. McCabe, J. F., Yan, Z., AL naimi, O. T., Mahmoud, G., Rolland S. L. Smart material in dentistry- future prospects. Dent Mater 2009; 28 (1): 37-43.

24. Angeles, M., Lorente, C., Godin, C., and Meyer, J. Mechanical behavior of glass ionomer cements affected by long-term storage in water. Dent Mater 1994; 10: 37-44. 